\section{Defining thought broadcast}

\author{
Semi-structured literature review
}

AJAYKUMAR V. PAWAR and SEAN A. SPENCE

\begin{abstract}
Background The symptom of thought broadcast may have diagnostic significance but its definition varies.
\end{abstract}

\begin{abstract}
Aims To examine multiple definitions of thought broadcast in different texts, to synthesise their common features and to undertake local and national surveys of psychiatrists to determine which definitions they endorse.
\end{abstract}

Method A semi-structured literature review of electronic databases, supplemented by a manual search of psychiatric textbooks, conceptual analyses and postal surveys of clinicians in NorthTrent (58 trainees and 70 consultants) and throughout the UK (49 professors of general adult psychiatry).

Results Thought broadcast is susceptible to multiple definitions: three exemplars were identified in the literature, each endorsed by influential authors. Among those psychiatrists responding to the survey (approximately $59 \%$ ), some endorsed each definition of thought broadcast.

\section{Conclusions Thought broadcast} means different things to different people. Inconsistent terminology might impair communication in clinical and research contexts.

Declaration of interest None.
Emil Kraepelin was possibly the first to describe thought broadcast in his seminal work Psychiatrie (1913), in the sections published in English as Dementia Praecox and Paraphrenia in 1919. Since then, the concept has been incorporated into most accounts of Schneider's first-rank symptoms of schizophrenia and has assumed ICD-10 diagnostic significance (World Health Organization, 1992). In the absence of an organic or mood disorder, thought broadcast may be sufficient to diagnose schizophrenia, notwithstanding empirical evidence of its non-specificity (e.g. Peralta \& Cuesta, 1999). Although the diagnostic application of the first-rank symptoms of schizophrenia has attracted controversy (Crichton, 1996), the symptoms themselves also are problematic in that they are inconsistently defined (Koehler, 1979; Mullins \& Spence, 2003). We have been impressed by the varied definitions of thought broadcast cited in the literature and have studied its use by contemporary psychiatrists.

\section{METHOD}

\section{Literature review}

We performed a semi-structured literature review using electronic databases (Biological Abstracts, Medline, Embase, Philosopher's Index), entering the keywords THOUGHT BROADCAST, FIRST RANK SYMPTOMS, SCHNEIDER, THOUGHT TRANSFERENCE, THOUGHT ALIENATION and THOUGHT DIFFUSION for the years 1975-2000. A manual search of classic textbooks and journal articles also was undertaken, examining the years 1919-1975. Our purpose was to ascertain a range of definitions of thought broadcast (not necessarily to locate all definitions of thought broadcast). Of the 144 references collected, 49 provided definitions of sufficient detail to be relevant and these were studied closely.
We then examined the central features of the thought broadcast concept by comparing the various definitions provided in the published literature. Based on these central features, we distilled three possible definitions of thought broadcast (see Results section). Each definition enjoyed influential proponents and in the absence of a gold standard it is not possible to say which is 'correct'. However, the three definitions appear to be mutually inconsistent.

\section{Postal surveys}

In the next stage of the study, we distributed a short questionnaire to all consultant psychiatrists and senior house officers on a psychiatric training scheme in the north of England (North Trent). The questionnaire offered three non-attributed but legitimate (i.e. published) definitions of thought broadcast and respondents were asked to indicate which they thought were correct. They were also provided with space to compose their own definitions. The questionnaires were anonymous and only one mailing was used. Stamped addressed envelopes were supplied for replies. We allowed 10 weeks for receipt of completed responses.

Finally, we repeated this process in a survey of professors of 'general adult psychiatry' in the UK (using a database obtained from the Royal College of Psychiatrists). We excluded those professors who might have responded to the previous survey (in North Trent). Once again, the questionnaires were unmarked and sent only once (with stamped addressed envelopes). We allowed 10 weeks for completed replies.

\section{RESULTS}

\section{Literature review}

Multiple definitions of thought broadcast exist in the literature and, although some are broadly similar, important differences emerge. We located three different variations on the definition of thought broadcast, each of which described distinct phenomena.

Definition 1 The patient hears his own thoughts being spoken aloud and, as a consequence, other people are able to hear his thoughts as well.

This first definition, distilled from published sources, hinges on thoughts becoming audible first, before they can be 
'heard' by others. Hence, it seems to imply that an auditory hallucination is integral to the phenomenology. This definition can be regarded as specific, or 'narrow', in that the experience of other people is also essential to its formulation (other definitions of thought broadcast are less specific on this point; see below)

We found the first reference to this definition in Kraepelin's Dementia Praecox and Paraphrenia (pp.12-13):

'It is quite peculiar to dementia praecox that the patient's own thoughts appear to them to be spoken aloud. .. [I]n consequence of this everything is made public. What the patients think in their own homes is proclaimed to everyone, so that their thoughts are common property'.

The Present State Examination (PSE; Wing et al, 1983) describes thought broadcast as being secondary to 'thoughts, which seem to sound aloud in the patient's head'. If 'audible thoughts' are present on their own then they are rated as 1 on the PSE; 'sharing of thoughts' acquires a rating of 2 , i.e. the full rating for thought broadcast.

Andreasen (1984), in the Scale for Assessment of Positive Symptoms (SAPS), takes a similar view:

'the subject believes that his thoughts are broadcast so that he or others can hear them. Sometimes the subject experiences his thoughts as a voice outside his head; this is an auditory hallucination as well as a delusion'.

A contemporary psychiatric textbook (Gelder et al, 1996: p. 14) concurs:

'Some patients . . . believe that their thoughts can be heard by other people (a belief which also accompanies the experience of hearing one's thoughts spoken)'.

Hence, definition 1 resembles an auditory hallucination (although the 'location' of the spoken thoughts may be internal or external to the head). It is worth noting that 'thoughts spoken aloud' (Gedankenlautwerden) were construed as hallucinations by Schneider (1959) and distinguished from thought broadcast.

Definition 2 The patient experiences his thoughts as escaping silently; they may or may not be available to other people.

This definition does not stipulate that thoughts become audible. They are perceived as escaping silently, with no mechanism being specified as to how they escape (cf. thought withdrawal) or how they become available to others. It is also a 'broad' definition, in that it need not implicate the experience of others (cf. definition 1). However, it may be interpreted narrowly if one insists that thoughts have to be known to others.

Mellor (1970) provides a prototypical example:

'A 21-year-old student said, "As I think, my thoughts leave my head on a type of mental ticker-tape. Everyone around has only to pass the tape through their mind and they know my thoughts"'.

Mellor (1970) defines thought broadcast as occurring when

'thoughts escape from the confines of the self into the external world, where they may be experienced by all around' (italics added);

this is a broad definition. Cutting (1995), in Hirsch \& Weinberger's Schizophrenia, defines a somewhat narrower thought broadcast, occurring when 'thoughts escape into outside world where they are experienced by others' (p. 20).

Koehler (1979), examining the definitions of the first-rank symptoms of schizophrenia offered by four prominent authors of the period, described thought broadcast as a 'negative-passive experience of alienation' (p. 239). Specifically,

"[the] subject is quite certain of "negatively" being aware that he has lost HIS OWN thoughts, feelings and so on because in some way they passively diffuse into or are lost to the outside world against his will' (original capitals, italics added).

The contrast here is with thought withdrawal, in which

the subject... has lost HIS OWN thoughts, feelings and so on because they have been actively taken away from without' (p. 239, original capitals, italics added)

Koehler (1979) also commented on a definition offered by Taylor \& Heiser (1971), in which:

"the subject has the experience "that as his thoughts occur they are escaping from his head into the external world" (sic)... for Taylor and Heiser the actual sharing of the diffused thoughts was not considered an essential requirement for a positive rating'.

However, although these authors might indeed imply a broad definition of thought broadcast, there is an important inaccuracy in Koehler's citation. The original reads:

'as his [the patient's] thoughts occur they are escaping from his head aloud into the external world' (Taylor \& Heiser, 1971: p. 484: italics added).

Hence, although Mellor, Koehler and indeed Schneider (1959) describe a 'silent' thought broadcast, differentiating it from Gedankenlautwerden, Taylor \& Heiser seem to conflate these phenomena (as do the SAPS and PSE), with resulting confusion in the ensuing line from their original paper: 'This experience is not an hallucination...' (Taylor \& Heiser, 1971: p. 484; an interpretation directly contradicted by Andreasen, 1984).

O'Grady (1990) used alternative definitions of the first-rank symptoms of schizophrenia in an attempt to differentiate schizophrenia from other acute psychoses: in thought broadcast,

'either thoughts leave the confines of the subject's mind but are not shared or they are so loud that others can hear them' (p. 497)

The first of these alternatives is not explicitly an auditory phenomenon (consistent with our definition 2) but the second clearly is (our definition 1). Also, the first is a broad definition (thought sharing does not occur), whereas the second is clearly narrow (thoughts are shared by others).

Hence, a number of the commonly cited papers and assessment tools describing thought broadcast seem to contradict each other as to whether thought broadcast involves thoughts being known to others, whether this is a 'consequence' of Gedankenlautwerden and, if so, whether a 'spoken' thought constitutes an hallucination.

Definition 3 Thought broadcast is the result of other people being able to think in unison with the patient, being able to participate in his thoughts or share the patient's thoughts directly by some other means.

This definition is different from the first two in a number of respects: it does not depend upon thoughts becoming audible; it is a narrow definition (i.e thoughts must be available to others); and someone other than the patient shares in their agency.

This is perhaps the most pertinent definition, in this context, because it is the view adopted by Schneider (1959). Although he did not use the term 'thought broadcast', Schneider described 'diffusion of thought', 'thought diffusion' or Gedankenausbreitung:

'Equally important are the thoughts which are no longer private but shared by others, the whole town or the whole world. To this symptom, the direct participation of others in the patient's thoughts, we have given the title "expropriation of thoughts" or "diffusion of thoughts"' (p. 100).

Fish (1967: pp. 39 and 79) and Jaspers (1962) describe similar phenomena (although Jaspers does not use the term thought broadcast). As Koehler (1979: p. 243) comments on Fish (1967: p. 39):

'Fish's definition of this phenomenon seemed rather narrow: the subject "knows that as he is thinking everyone else is thinking in unison with 
him"... Apparently the actual sharing of thoughts remains an essential criterion in his description so that the mere diffusion of thoughts from the patient's head would not suffice to merit a positive rating' (cf. definition 2).

Jaspers (1962: p. 127) comments:

'Patients notice that other people know their thoughts as soon as they have them. Or, in a way similar to passivity thinking and thought withdrawal, they experience the feeling of being exposed to everybody. "I believe I can no longer hide anything....all my thoughts have been guessed. I realise I can no longer keep my thoughts to myself"'.

Sims (1988) also comments on this element of passivity in thought broadcast (p.119) and Landmark's (1983) Manual for the Assessment of Schizophrenia (MAS) describes thought broadcast (item 83) as 'diffusion of thoughts', implicating the 'participation' of others and the 'reading' of thoughts, with no mention of their audibility (p. 39).

\section{Postal surveys}

Having determined that thought broadcast may be variably described in the literature, we examined whether this was reflected among contemporary clinicians and academics. In two anonymous surveys we offered clinically active psychiatrists three possible definitions of thought broadcast (definitions 1-3).

In the first survey, within North Trent, we obtained a satisfactory response from consultant psychiatrists (Table 1), although the response from senior house officers was a little disappointing (just less than half). However, in both groups we found a similar response profile to definitions of thought broadcast. Although one-fifth of those surveyed endorsed more than one definition, more than $60 \%$ of each sample's respondents preferred definition 1. However, some respondents (particularly consultants) endorsed definitions 2 and 3.

In view of the possibility that concordance among local respondents might merely reflect local patterns of teaching and practice, we undertook a second postal survey of professors of general adult psychiatry in the UK. Their replies were (perhaps surprisingly) similar to those of doctors within North Trent. Once again, most endorsed a single preferred definition and most preferred definition 1. However, there was substantial support also for definitions 2 and 3 (Table 1).

\section{DISCUSSION}

\section{Conceptual ambiguities}

Thought broadcast is a symptom that may be used to diagnose schizophrenia (ICD10), despite its non-specificity (e.g. Peralta \& Cuesta, 1999). However, the definition of thought broadcast is susceptible to critique. We have elucidated three possible uses of the term, each derived from respected sources. Essentially, these definitions contradict each other. From a phenomenological perspective, they seem to describe distinct phenomena: involving thoughts that are heard aloud (Gedankenlautwerden; Sims, 1988: p.121); a process occurring in silence; and requiring the 'participation' of other agents. More problematic, perhaps, is the absence of any single phenomenological component that might be said to be common to these definitions, while concurrently differentiating thought broadcast from other psychotic

Table I Results of postal surveys

\begin{tabular}{|c|c|c|c|c|}
\hline & $\begin{array}{l}\text { Total sample } \\
\qquad(n=177)\end{array}$ & $\begin{array}{l}\text { Senior house } \\
\text { officers }^{\prime} \\
\quad(n=58)\end{array}$ & $\begin{array}{l}\text { Consultants }{ }^{2} \\
\qquad(n=70)\end{array}$ & $\begin{array}{c}\text { Professors } \\
(n=49)\end{array}$ \\
\hline Response rate & $104(58.8 \%)$ & $28(48.3 \%)$ & $44(62.9 \%)$ & $32(65.3 \%)$ \\
\hline $\begin{array}{l}\text { Respondents endorsing a single } \\
\text { definition }\end{array}$ & $84(80.8 \%)$ & $23(82.1 \%)$ & 35 (79.5\%) & $26(81.3 \%)$ \\
\hline $\begin{array}{l}\text { Respondents endorsing more than } \\
\text { one definition }\end{array}$ & 20 (19.2\%) & $5(17.9 \%)$ & 9 (20.5\%) & $6(18.8 \%)$ \\
\hline Respondents endorsing definition I & $64(61.5 \%)$ & $19(67.9 \%)$ & $27(6 \mathrm{I} .4 \%)$ & $18(56.3 \%)$ \\
\hline Respondents endorsing definition 2 & $2 \mathrm{l}(20.2 \%)$ & $3(10.7 \%)$ & $7(16.0 \%)$ & II (34.4\%) \\
\hline Respondents endorsing definition 3 & $4 \mathrm{l}(39.4 \%)$ & II (39.3\%) & 19 (43.2\%) & II (34.4\%) \\
\hline
\end{tabular}

I. One response was not counted owing to ambiguity.

2. Four responses were not counted owing to ambiguity.

phenomena. To satisfy at least one definition of thought broadcast it is not absolutely necessary that thoughts be spoken aloud, nor is it essential that they be heard by others or even known to them. The single feature shared by definitions 1 and 2 (it is not absolutely necessary for definition 3) is that thoughts are perceived as leaving the subject's head/mind; however, this component is shared with thought withdrawal (their differentiation explicated by Koehler, 1979). Although it might be countered that using the term 'thought diffusion' as an alternative to thought broadcast might be pragmatic when describing the 'silent' loss of thoughts, this application might also precipitate confusion. Although Schneider used this term (and not thought broadcast) in his list of the first-rank symptoms of schizophrenia, it is nevertheless commonly translated as thought broadcast in contemporary textbooks (e.g. Sims, 1988; Cutting, 1995; Wing, 1995). Hence, the vocabulary of the first-rank symptoms of schizophrenia would have to be modified, consistently, if such an adjustment were to be made.

\section{Problems for pathophysiology}

If the current, varied, definitions of thought broadcast were to form the basis of a neurobiological investigation into the pathophysiology of the first-rank symptoms of schizophrenia, their conflation (across studies and investigators) might obscure important differences in underlying cerebral processes.

Even though it might be argued that the impact of such variation upon research data is less pronounced if operational criteria are applied within studies (e.g. the SAPS or MAS), confusion might still arise if comparisons were made across studies (because these operational criteria differ between themselves).

\section{Clinical ambiguities}

Is thought broadcast variably defined in the clinic? Our postal surveys cannot reveal how practising psychiatrists use this term clinically. However, our findings indicate a degree of divergence when they are confronted by contrasting definitions (as might be envisaged in professional examinations). Although most respondents endorsed our first exemplar (definition 1), synthesising the descriptions of Kraepelin, Andreasen and others, at least one-third endorsed a definition derived from 
Schneider, Fish and Jaspers (definition 3). Our second exemplar (definition 2), derived from Mellor, Koehler and others, was generally less well supported, although even here one-third of professors endorsed the definition.

An ancillary question arises, namely: what is the response of psychiatrists to phenomena that they do not recognise as constituting thought broadcast? For instance, if a psychiatrist endorsing definition 1 should encounter a patient describing phenomena akin to definition 2, what might the psychiatrist call the symptom? We cannot answer this question on the basis of our study.

\section{The need for clarity}

Although our surveys suffer from the disadvantages of anonymous postal surveys, and response rates were at the border of acceptability (approaching 60\%), certain aspects bear consideration. In each sample, the same gradation was observed across definitions, with definition 1 being preferred. Also, approximately one-fifth of those responding (in each context) endorsed more than one definition. This suggests that across grades (trainees and consultants) and contexts (full-time clinicians and academics) there is a variety of opinion regarding what thought broadcast means. Hence, unless phenomenology is clearly described in case notes and correspondence, it is conceivable that 'thought broadcast' is variably construed by authors and readers.

Thought broadcast is a concept that has been central to the description, diagnosis and understanding of schizophrenia, yet it is susceptible to multiple definitions. We have described three contrasting definitions, each of which is endorsed by influential authors in the field. When contemporary physicians were surveyed in local, national, training grade, consultant and professorial settings, some of those responding endorsed each definition. Thought broadcast means different things to different people.

\section{ACKNOWLEDGEMENTS}

We are grateful to the Sheffield Care Trust and the University of Sheffield Academic Department of Psychiatry for support, to the Royal College of Psychiatrists for access to its membership data; to Mrs Jean Woodhead for technical assistance, to all those who responded to the postal questionnaires and to the anonymous referees for their helpful comments.

\section{CLINICAL IMPLICATIONS}

- The symptom of thought broadcast has been used to diagnose schizophrenia, yet its definition varies between authors and practitioners.

- To most respondents in a questionnaire survey, thought broadcast involved thoughts being 'spoken aloud', in contrast to Schneider's classification of the first-rank symptoms of schizophrenia.

- In clinical and research settings it may be preferable to describe the phenomenology in detail, because readers may construe thought broadcast in at least three different ways.

\section{LIMITATIONS}

- The initial literature review was confined to English-language sources (and translations) and excluded primary texts in other languages.

Most of the definitions applied are subtle and may be elicited variably in the clinic.

- Although stable definitions are a prerequisite for pathophysiological research, they may have no implications for treatment (at the present time).

AJAYKUMAR V. PAWAR, MRCPsych, SEAN A. SPENCE, MRCPsych, Academic Clinical Psychiatry, University of Sheffield, UK

Correspondence: Dr Sean A. Spence, Reader in General Adult Psychiatry, Academic Clinical Psychiatry, Division of Genomic Medicine, University of Sheffield, The Longley Centre, Norwood Grange Drive, Sheffield S5 7JT, UK. Tel: +44 (0) II4 22 61519; fax: +44 (0) II422 61522; e-mail:

S.A.Spence@Sheffield.ac.uk

(First received 20 January 2003, final revision 6 May 2003, accepted 6 May 2003)

A full list of the articles reviewed is available from the authors upon request.

\section{REFERENCES}

Andreasen, N. C. (1984) Scale for Assessment of Positive Symptoms (SAPS). lowa City, IA: University of lowa.

Crichton, P. (1996) First-rank symptoms or rank-andfile symptoms? British Journal of Psychiatry, 169, 537-540.

Cutting, J. (1995) Descriptive psychopathology. In Schizophrenia (eds S. R. Hirsch \& D. R. Weinberger), pp. 15-27. Oxford: Blackwell Science.

Fish, F. (1967) Clinical Psychopathology, Signs and Symptoms in Psychiatry. Bristol: J.Wright \& Sons.

Gelder, M., Gath, D., Mayou, R., et al (1996) Oxford Textbook Of Psychiatry, pp. 13-15. Oxford: Oxford University Press.

Jaspers, K. (1962) General Psychopathology (English translation). Manchester: Manchester University Press.

Koehler, K. (1979) First rank symptoms of schizophrenia: questions concerning clinical boundaries. British Journal of Psychiatry, I34, 236-248.
Kraepelin, E. (1913) Psychiatrie: ein Lehrbuch für Studirende und Aertze (8th edn). Leipzig: Barth Verlag. Selected chapters reprinted in translation as Dementic Praecox and Paraphrenia (1919) (ed. G. M. Robertson; trans. R. M. Barclay), reprinted 197I, Huntington, NY Robert E. Krieger.

Landmark, J. (1983) A manual for the assessment of schizophrenia. Acta Psychiatrica Scandinavica Supplementum, 298, I-88.

Mellor, C. S. (1970) First rank symptoms of schizophrenia. I. The frequency in schizophrenics on admission to hospital. II. Differences between individual first rank symptoms. British Journal of Psychiatry, II7, 15-23.

Mullins, S. \& Spence, S. A. (2003) Re-examining thought insertion. Semi-structured literature review and conceptual analysis. British Journal of Psychiatry, $\mathbf{1 8 2}$, 293-298.

O'Grady, J. C. (1990) The prevalence and diagnostic significance of Schneiderian first-rank symptoms in a random sample of acute psychiatric in-patients. British Journal of Psychiatry, 156, 496-500.

Peralta, V. \& Cuesta, M. J. (1999) Diagnostic significance of Schneider's first-rank symptoms in schizophrenia. Comparative study between 
schizophrenic and non-schizophrenic psychotic disorders. British Journal of Psychiatry, 174, 243-248.

Schneider, K. (1959) Clinical Psychopathology (English translation by B. A. Hamilton). New York: Grune \& Stratton.

Sims, A. (1988) Symptoms in the Mind. An Introduction to Descriptive Psychopathology. London: Baillière Tindall.
Taylor, M. A. \& Heiser, J. F. (197I) Phenomenology: an alternative approach to diagnosis of mental disease. Comprehensive Psychiatry, I5, 480-486.

Wing, J. K. (1995) Concepts of schizophrenia. In Schizophrenia (eds S. R. Hirsch \& D. R. Weinberger) pp. 3-14. Oxford: Blackwell Science.
_, Cooper, J. E. \& Sartorius, N. (1983) Present State Examination (9th edn). Cambridge: Cambridge University Press.

World Health Organization (1992) The ICD-10 Classification of Mental and Behavioural Disorders. Geneva: WHO. 